\title{
Managing Without Blame? Insights from the Philosophy of Blame
}

\author{
Ben Lupton ${ }^{1} \cdot$ Richard Warren ${ }^{1}$
}

Received: 31 July 2015/Accepted: 21 July 2016/Published online: 2 September 2016

(c) The Author(s) 2016. This article is published with open access at Springerlink.com

\begin{abstract}
This article explores the concept of blame in organizations. Existing work suggests that 'no-blame' approaches (or cultures) may be conducive to organizational learning and may foster innovation. However, both the apparently strong public appetite for blaming, and research into no-blame approaches, suggest that wider application of 'no-blame' in organizations may not be straightforward. The article explores the contribution of the rich philosophical literature on blame to this debate, and considers the implications of philosophical ideas for the no-blame idea. In doing so, it identifies conceptual and practical issues, sheds light on why the benefits of 'noblame' may be difficult to realize, and offers the basis for an alternative approach. The article also contributes by providing foundations for future research, and identifies some fruitful lines of enquiry.
\end{abstract}

Keywords Blame Communities of practice Errorreporting · Leadership · Organizational learning · Philosophy · Virtue ethics

\section{Introduction}

There has been a developing interest-in public, professional, and academic discourse - in the idea of fostering 'no-blame' approaches (or cultures) in organizations. A

Ben Lupton

b.lupton@mmu.ac.uk

Richard Warren

r.warren@mmu.ac.uk

1 Business School, Manchester Metropolitan University, Oxford Road, Manchester M15 6BH, UK central theme is whether blame may be a barrier or inhibitor to organizational learning (Vince and Saleem 2004; Shilling and Kluge 2009; Provera et al. 2010; Tjosvold et al. 2004; Gronewold et al. 2013; Uribe et al. 2002; Busby 2006). If employees are free from the fear of blame, they may be more likely to be open about errors and engage with others in learning from them, enabling the organization to identify problems and make systemic improvements to its operations (Provera et al. 2010). A second consequence may be that employees are liberated to take risks and to innovate, potentially contributing to the firm's competitive advantage (Farson and Keyes 2002). However, this literature also recognizes that difficulties exist in developing and sustaining no-blame cultures in practice, and that the ability to do so may depend on organization type and context (Provera et al. 2010).

Philosophers (e.g. Wallace 1994; Scanlon 2008) have devoted a good deal of attention to exploring the nature of blame and understanding its place in our lives, often reaching widely divergent conclusions with potentially profound implications. However, the organizational noblame literature rarely recognizes or addresses this, or makes explicit its assumptions about the nature of blame. It seems conceivable that insights from the philosophical literature on blame may enrich organizational thinking on blame, and shed light on some of the difficulties surrounding the concept of no-blame.

The purpose of this article is to establish points of connection between the organizational no-blame literature and the body of philosophical writing on blame. We consider the extent to which the latter has purchase on organizational thinking around blame, paying specific attention to the issue as to whether philosophers and organizational writers are working with the same conception of blame. We explore the extent to which philosophical ideas may be 
implicit in no-blame thinking, their potential to put ideas around organizational blame onto a firmer theoretical footing, and how the no-blame idea may be evaluated in relation to the philosophy of blame. We also consider whether the philosophical debates point to alternatives to no-blame.

The article is exploratory in nature. By opening a dialogue between two apparently related but currently parallel literatures, its aim is to do some groundwork for future research. As a 'first cut' at this endeavour, the article does not seek to offer substantive conclusions as to the merits of the no-blame idea in the light of the philosophical reasoning. Rather its contribution lies in identifying where the main conceptual and practical issues might lie, and offering some thoughts on how they might be approached. In doing so, it provides a foundation for future theoretical and empirical work on the subject.

The article starts with a review of the organizational noblame literature before offering a synthesis of the extensive philosophical literature on blame. This provides a foundation for a discussion of the implications of the philosophical literature for an understanding of organizational (no-) blame. The article proceeds to reflect on possible limits to applying philosophical concepts to blame in organizations. It concludes by considering an alternative to no-blame and identifying an agenda for future theoretical development and empirical enquiry.

\section{No-Blame Cultures}

‘... I don't do blame ... Blame will not produce anything productive at all.' Sharon Shoesmith, former Director of Haringey Social Services (UK), responding to questions in a BBC radio interview (28/ 3/2011) following the 'Baby $P$ ' child abuse case (BBC 2011)

'Looking for someone to blame might satisfy our base desire but will it really help us next time around?' (Holmes 2010, p. 389. following the Victoria bushfires, Australia)

'[we should A]bandon blame as a tool, and trust the goodwill and good intentions of the staff.' (NAGSPE 2013, p. 4, 'the Berwick Report' on patient safety in the UK National Health Service, following patient mistreatment scandals)

"We have to have a proper analysis rather than scapegoating and "blame gaming".' (BBC 2015, Harriet Harman, Acting Leader of the UK Labour Party, following defeat in the 2015 General Election)

These quotations reflect a recurring strand in public discourse that there may be something unproductive, or even counter-productive, about blaming someone when something goes wrong. At best, it seems, blaming may be a misuse of energy and resources; at worst, it may inhibit learning from mistakes and making improvements-a view captured by Admiral Lang in his comments on the Costa Concordia cruise liner disaster: '... I pray that the apparent desire to apportion blame will not undermine the overriding need to identify the key issues that underpin this terrible accident' (Lang 2013, p. 21).

Both Holmes and Lang allude to a tension between a tendency towards blaming and the potential benefits of refraining from doing so. We shall explore this tension later in the article. However, this public commentary in the wake of major disasters around the utility of blame also reflects an emerging theme in the management literature concerned with the development of no-blame cultures in organizations, the benefits they may bestow, and difficulties that might be encountered in developing and nurturing them. We start by examining this literature.

Provera et al. (2010, p. 1058) define 'no-blame' as 'an organizational approach characterized by a constructive attitude towards errors and near misses'. Central to this is the idea that human error is inevitable, but that systems are open to improvement. In a no-blame approach, the focus is moved away from identifying the perpetrator(s) of the error (often with associated shame or punishment) to identifying the lessons that could be learned so that processes can be improved. The focus is on organizational learning (Senge 2006; Vince and Saleem 2004), and the underlying logic is that an organization's blaming practices may be amongst the things that inhibit this (Provera et al. 2010; Schilling and Kluge 2009), as these may focus management energy and effort on identifying individual(s) responsible for a mistake, rather than on the more productive activity of examining wider systems that require adjustment if the error is not to be repeated. In addition, by discouraging the reporting of mistakes or near-misses by individuals (Waring 2005), blame cultures may make organizational learning from these events impossible. ${ }^{1}$ Finally, blaming practices may inhibit the participation of individuals in learning when their errors have come to light, with the consequence that employees who are concerned with defending themselves, or deflecting blame, will be unlikely to engage in collective reflection or contribute to wider learning (Vince and Saleem 2004). Provera et al. also note that no-blame approaches, through an acceptance of error and openness around an event, can help organizations to avoid learning the 'wrong things' (2010, p. 1059), such as being fatalistic about error or over-confident in the ability of their systems to avoid it—in other words, to steer a path

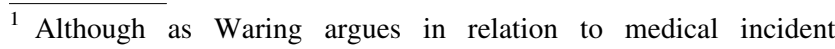
reporting, blame cultures may not be the only culprit here, and that the wider context of professional cultures need to be considered.
} 
between the destructive effects arising in 'blame cultures' from either an excessive fear of blame or from a perceived immunity from it.

In avoiding these negative consequences of blame, the no-blame approaches identified by Provera et al. (2010) typically involve the following elements (Weick and Sutcliffe 2001): firstly, error-reporting procedures that are 'safe' for individuals, and which actively encourage the recording and reporting of problems and 'near-misses' (Gronewold et al. 2013). Secondly, processes for reflecting on errors and problems, and learning from them, that are inclusive (not least of those who have reported or experienced them) and holistic, i.e. that look for both proximal and distal causes across wider organizational systems. Thirdly, systems for identifying and implementing improvements, which are then communicated positively and openly. It is here that we can see why the term '(no-)blame culture' (Vince and Saleem 2004) is sometimes used, as all three of these elements rely on certain values and assumptions being present amongst employees and managers; a willingness to be open about mistakes, a trust that managers will not abuse this openness, a culture of involvement and sharing knowledge across hierarchies and departmental boundaries, and a practice of developing and celebrating positive narratives around error resolution - the 'story of the error', as Provera et al. (2010, p. 1059) put it.

A second benefit of a no-blame culture may lie in the encouragement of risk-taking and innovation. Most organizations will require employees to take risks of some sort, though the magnitude and nature of these risks will vary. Creative or research-based industries are very obvious environments where risk-taking is required, but in more mainstream organizations there are risks in developing products, entering new markets, and offering or withdrawing services. Where managers and employees operate in a climate where they are blamed for failure, innovation and risk-taking are likely to be stifled (Farson and Keyes 2002; Schilling and Kluge 2009). Vince and Saleem (2004) show that this relationship is not one way, but that caution and blame can feed off each other. Caution can lead to the tendency to externalize problems by blaming others, and the resulting climate of blame in turn begets cautioninhibiting innovation (and also reflection and collective learning, as noted above). Not only may the desire to avoid blame, where this is a culturally prevalent practice, inhibit innovation, it also constrains the potential learning, individual and organizational, that might arise from that. There is concern, for example, that doctors may avoid introducing new and/or potentially risky procedures in a climate where their failure rates are made public, and this might apply more widely to the organizations they work for, which may have objectives to preserve league table positions. The same may apply in education, to teachers developing new approaches, or university lecturers developing new courses.

Despite these espoused advantages of no-blame approaches, and the apparent anti-blame zeitgeist (Sher 2006; Owens 2000, 2012; Franklin 2013), it is not clear how widely the concept of no-blame is applied in organizations. As Provera et al. (2010) point out, much of the extant research has concerned itself with no-blame approaches in what the authors call High Reliability Organizations (HROs). These are organizations that operate with constant risk of large-scale disaster (airlines, nuclear installations, shipping lines, etc.), and thus have a need for highly reliable operating systems. Here, the heightened imperative to avoid high-impact error creates an environment where it is possible (and, arguably, necessary) to have a no-blame approach so that the necessary organizational learning can take place to prevent future catastrophe. Indeed, there is an incentive for minor errors and near-misses to be embraced as they generate positive opportunities for improvements in systems. However, the benefits may be less obvious in organizations that do not operate under the constant risk of catastrophe. Indeed, noblame approaches may not offer benefits alone. Busby (2006) provides an example of an unfortunate side-effect of no-blame in the rail industry, where train drivers readily accepted attribution of error as there was no blame apportioned, and this actually inhibited investigation of systemic failures.

As Provera et al. (2010) show, there are operational costs to implementing no-blame approaches-in time devoted to developing and operating processes designed to learn from error, staff development, and overcoming existing structural and cultural barriers, for example, hierarchies, vertical communication systems, top-down management styles, and cultures of error denial in the context of regulatory and litigious environments. The question arises as to whether these costs are justifiable for more mainstream organizations in the context of their relative lack of exposure to risk of large-scale disaster. Of course, as Provera et al. (2010) acknowledge, the dividing line between HROs and other organizations is not clear cut. Recent experience tells us that organizations not (previously) readily associated with major risk, for example banks or broadcasting companies, may experience farreaching human and corporate disasters. ${ }^{2}$ In any case, as these authors conclude, the benefits of organizational learning enabled by no-blame approaches are potentially universal, so there would be no a priori reason to rule out the extension of no-blame practices more widely.

\footnotetext{
${ }^{2}$ Illustrated, for example, by the collapse of Lehman Brothers, and the Jimmy Savile scandal at the BBC.
} 


\section{What is Blame?}

No-blame approaches, it seems, have much to recommend them, and-costs notwithstanding-there appears to be a good case for extending their application more widely than to the high-risk organizations where they have received most attention. However, we wish to argue here that such a conclusion would rest on infirm ground without an understanding of the nature of blame and its place in human life. Whether we should, or indeed can, dispense with blame-or constrain it—surely depends on what we think blame is. One of the curious features of the literature concerned with no-blame cultures and approaches is that it very rarely considers-at least explicitly - the ontology of its central concept. Philosophers have devoted considerable attention to unpacking blame and blaming practices, reaching profoundly diverse conclusions which have important implications for our understanding of blame in organizations. Our aim in this section is to provide a firmer foundation for an exploration of the no-blame concept by exploring the philosophy of blame.

We start by considering a position which has a long tradition in utilitarian philosophy, and which concords with many popular intuitions about blame. Under this conception, blame is regarded as a sanction, and one that is socially useful. According to this view, 'to blame someone is simply to express disapproval of his bad behaviour or character in a way that is calculated to mitigate or improve it' (Sher 2006, p. 72). It forms part of 'an economy of threats' (Wallace 1994, p. 54). Implicit here is the idea that the sanction works because blame is unpleasant to the recipient and recognition of this fact will cause him to avoid incurring it in future. Blame, in this account, is 'punishment light' (Sher 2006, p. 73). Also implicit in this approach is the view that blame is appropriate in respect of things people choose to do-there would be very little point in using blame as a sanction, if people could not choose to do differently next time. Thus, the utilitarian approach to blame links closely to a violitionist account of blame (Levy 2005), where blame is seen as being limited in its applicability to what people do voluntarily. A variation of this approach would be what Owens (2000) calls a juridical account of blame, where the scope of blame is extended a little more widely to encompass what people can control. The scope still remains narrow, not extending to, for example, aspects of people's character, for example their orientation towards others.

Despite its intuitive appeal, the utilitarian view of blame has come under sustained critique in the philosophical literature. One concern is around whether blame can sensibly be seen as a sanction, when it is not always expressed, or not expressed to the 'guilty' party—we often blame privately, or in confidence. Further, as Williams (1995) points out, justifying blame on the grounds of its efficacy rests on infirm ground, for blame's efficacy in modifying its target's behaviour depends on the latter accepting that the blame is justified-otherwise it will be simply ignored or resented. Moreover, we sometimes blame people who are not in a position to alter their future behaviour, such as historical figures or, in an organizational context, people who have retired or left. A second critique is that the sanction account of blame does not capture the character of blame. If it is true that we blame in order to influence future events, maximum impact might involve serious blame for a minor misdemeanour, while it might be more efficient for very serious moral transgressions to be ignored (i.e. not made subject to blame, Sher 2006)—however, people's intuition seems to be to dispense blame in relation to how badly they feel about the act that triggers the blame. This leads to a further point, that when we blame someone for something we tend to feel something (Tilly 2008). It appears that we do not apply blame dispassionately and purposefully in the same way as, for example a medical treatment. As Bennett argues, if the purpose of blame were to change behaviour, it would have a therapeutic character; however, when we blame, 'we are not usually engaged in any kind of therapy' (Bennett 1980, p. 20). Blame often involves an element of ill-feeling or even hostility, which is hardly calculating or therapeutic. It is open to the utilitarian to argue that we 'add' anger in order to give the blame more deterrent force, but again this seems to be rather an odd description of what we do when we blame someone. We do not appear to 'conjure up' (Bennett 1980, p. 22) emotions to accompany our blame, those emotions already accompany it, or may even be constitutive of it.

There are two main alternatives to the utilitarian view of blame. The first is associated primarily with Scanlon (2008), who argues that blame is a recognition and response to the impairment of a relationship that results from another's bad act or attitude. To blame a person is to '... take your relationship with him or her to be modified in a way that this judgment of impaired relations holds to be appropriate' (2008, p. 128). This idea of judging oneself to have been let down or having had, for example, a friendship damaged, would account for the force of blame in a way that the utilitarian account does not. Scanlon's account also offers an explanation for why blame is a necessary feature of human life. Scanlon views people as having obligations to one another-standing intentions to relate to others, while being responsive to reason in respect of these relations. Consequently, we have cause to think that other people have reasons to behave/be orientated in particular ways towards us (and others), and to call them to account when they do not respond to these reasons. Blame arises 
from these rational obligations, and indeed not to blame is to treat people as not rational, not responsive to reason in this sense. Following Scanlon's analysis, we can achieve an understanding not only of why people blame each other, but also an understanding of why they ought to (in appropriate circumstances).

There are a number of objections to Scanlon's position. The first is to suggest that blame is not necessarily relationship-based-we blame people with whom we have no prior relationship to impair, or for reasons that are not related to the impairment of a relationship. Addressing this point, Smith (2013) argues that it is better to see blame as a form of protest, a way of registering that a standard has been traduced, rather than a relationship impaired. Others question whether rationality, and the obligations that arise from that, are the basis of such relationships: 'We do not think of ourselves as having "ties" to other people solely in virtue of sharing with them the property of rationality' (Wallace 2008, p. 23). We can blame someone without regarding them as generally irrational and as not possible to engage with. The second objection is that Scanlon's account, like the utilitarian one, leaves the emotional component out of blame. Blame, in Scanlon's view, would be to judge someone to have transgressed, whereas it is alternatively argued that to blame is to care about that transgression. If one were to judge someone to be blameworthy, but not blame them (and one might), there would be something missing (Owens 2012), and this something is its emotional content. Blame, according to this view, has an element of opprobrium at the heart of it, something which is not central to Scanlon's account.

The second alternative view, then, is the 'affective' account of blame offered by Wallace and others. On this account, blame just is a negative feeling that we have when we feel that someone has acted badly, 'to blame someone ... is to be subject to a reactive emotion toward them' (Wallace 2008, p. 1), involving a 'withdrawal of [the] good will' (Sher 2006, p. 80) that we would otherwise have for people. These feelings - the reactive emotions of guilt, resentment, indignation (Strawson 1974) — are to us both primitive 'expressions of our emotional make-up' (Bennett 1980 , p. 24) and natural, 'in so far as they reflect our internalization of moral norms, as standards that govern our interactions with each other' (Wallace 2008, p. 12), our 'moral sentiments', as Wallace has it. Scholars argue that the existence of these feelings is what characterizes human interaction, in contrast to an 'objective attitude' (Strawson 1974 , p. 10) with which we might relate to a piece of machinery. Owens (2012) is more precise about the reactive emotion involved in blame-for him, it is a form of anger.

The affective account of blame, then, holds that blame is a natural human emotional response to being wronged or let down, and that human relations would be unintelligible without this class of emotional responses, of which blame is one. Indeed, it is possible to go further and argue that these reactive emotions are constitutive of meaningful human relations (Owens 2012; Franklin 2013). However, this account has its own difficulties, firstly those arising from the observation that we have already encountered, that we do not always feel or express anger when we blame someone. There have been different approaches to negotiating this difficulty. For example, Sher (2006) identifies a disposition to feel anger (or other emotions) which is present and characteristic of blame, but which may not always be expressed. Owens (2012) draws a distinction between appropriateness of blame as an angry reaction, and considerations of the aptness and desirability of feeling or expressing it. Blame can be defined as an appropriate emotional reaction without committing to the emotion being visible or appropriate in every case.

A similar argument is offered by Goldman (2014). Goldman broadly accepts the Strawsonian position that has underpinned the affective position on blame - that reactive attitudes are central to meaningful interpersonal relationships_-but argues that antagonistic attitudes such as anger need not be part of that suite of emotions. He suggests that a 'disappointed sadness' (2014, p. 15) would serve as an alternative reactive emotion to being wronged, and one that might be conducive to more constructive human relations.

Finally, we consider approaches to blame that are either sceptical of it per se, or questioning of the features of human society that underpin and sustain it as a social practice. The first is found in the work of philosophers (e.g. Pereboom 2001) who see determinism as incompatible with free-will, thus calling into question the notion of moral responsibility that underpins blame. Blame of any sort seems unjustified on that account. This line of reasoning sits uneasily with the sanction view of blame (above)-sanctions would be pointless if people are not free to do differently in the future. Emotions of resentment which underpin blame under some accounts would also seem inappropriate if one starts from that premise.

On the second point, Williams (1995) observed that our attachment to blame as a practice rests on the idea that we assume that the person we blame shares with us the reasons for not acting in a certain way-thus, their action resulted from not paying heed to these reasons (thus justifying the blame). Williams suggests that we are entitled to neither assumption, and regards blame as a fiction. To blame is thus to impose one's framework of reasons and values on another's behaviour or character and judge them in relation to it. Viewed in this way, judgments of blameworthiness, and the resulting blame, are forms of uninvited imposition upon us, and when viewed broadly, 'A continuing attempt... to recruit people into a deliberative community 
that shares ethical reasons' (Williams 1995, p. 16). A similarly 'critical' view of blame is contained in Nieztsche's idea $(1997,2003)$ that our moral judgments and our systems of morality grow out of feelings of 'ressentiment'-broadly speaking the fear and envy felt by the weak in relation to the strong. On this view our feelings of frustration at wrongdoing are motivated by feelings of envy and powerlessness in relation to others and our systems of morality_including blame-are inventions which allow us, however weak otherwise, to exert power over others through the judgments that they entitle us (on an equal footing) to make.

In this section, we have reviewed four different philosophical perspectives on blame-blame viewed as a sanction to shape future behaviour, blame viewed as a judgement on relationship impairment, blame viewed as an emotional reaction to someone having being wronged, and blame viewed as part of a social system of power relations. In the next section, we explore some of the implications of these approaches for the no-blame idea in organizations.

\section{Organizational Blame/No-Blame Reconsidered}

We now offer some thoughts on how organizational blame, and the no-blame idea, may be approached from the perspectives of the philosophy of blame. Given that the noblame literature is not on the whole explicit about its conception of blame, a preliminary task is to attempt to locate it within the philosophical debate on the basis of what is implied. The first observation is that the no-blame position is a consequentialist one, and blame is considered and evaluated with reference to its impact on future outcomes. Whether we should dispense blame, or refrain from doing so, depends on whether good-for example, organizational learning, appropriate risk-taking, disaster avoidance_-will follow from doing so. The desire to avoid blame serves as a control mechanism for management, or amongst colleagues, in ensuring that employees behave and perform to appropriate standards and avoid mistakes. Further, when blame is apportioned publicly it may have the effect of impacting on the future behaviour and performance of staff not directly involved. The value of a noblame approach to an organization can be evaluated in terms of the expected benefits, for example arising from enhanced organizational learning, and set against the costs, arising for example through implementation or from loss of management control. This approach underpins discussions as to whether no-blame approaches may be more desirable and practicable in some organizational settings than in others (Provera et al. 2010).

One interpretation would be to see this as congruent with the utilitarian approach to blame discussed earlier. On this interpretation, blame acts as sanction to shape behaviour, yielding benefits to the organization, yet this sanction itself may incur greater costs (in terms of loss of learning, risk-taking, etc.). The overall utility calculation may favour the removal of the blame. This is not to suggest that organizations explicitly make this calculation, but this might be proposed as the underlying logic. An argument against this view would be that consequentialist thinking of organizations-as goal-orientated entities they are bound to do this-does not in itself imply a particular conception of blame. However blame is understood, organizations (and organizational thinkers) could take a stance on whether in some circumstances (or generally) they would be better off without it. More generally, the evaluation of blame could then proceed independently from a discussion of its nature.

There is something to be said for this argument. For example, even if blame were conceived as an emotional response to things going wrong-i.e. under the 'affective' account of blame-it would still be unpleasant to the recipient, and individuals would presumably modify their behaviour to avoid it. Identifying the no-blame position as utilitarian on these grounds seems unwarranted. That is not to say that it is necessarily wrong, as it is unclear what conceptualization of blame underpins no-blame approaches.

However, it is not clear that the separation of the evaluation of blame from considerations of its nature is fully justified, at least in the context of this debate. Whatever the conception of blame that implicitly underlies no-blame thinking, it must be of a type that those advocating noblame think can practicably be suspended in order to achieve the desired consequences. It seems legitimate to consider whether different conceptions of blame are equally 'suspendable' in this sense. There is an argument to suggest that actions forming part of a deliberative system of sanctions may be more easily suspended, than an emotional response to wrongdoing. If blame is understood as a reactive emotion, and further, one that is constitutive of meaningful human relations (Strawson 1974; Wallace 1994; Owens 2012), this at least raises questions around how successful organizations might be in attempting to do without blame, even when they have calculated that it is desirable so to do.

Clearly, some care is needed in pursuing this line of argument. Firstly, it assumes a monolithic conception of blame, yet as we discuss in more detail in the next section, blame in organizational settings (and elsewhere) may take different forms. Some organizational blame will be of a 'whodunit' (Coates and Tognazzini 2013) or 'causal' type (Vincent 2011), and may have no emotional or judgmental content. Similarly, it rather assumes that we have no control over our moral emotions and how we dispense them. Even those philosophers who are sympathetic to the 
'reactive attitudes' discuss the appropriateness of these reactions and our ability to modify and temper them (Owens 2014; Goldman 2014). There is an argument to say that this is particularly the case in the context of organizations, which are controlled environments where people are socialized into modifying or tempering behaviours, perhaps particularly emotions, which would not be tolerated outside of the workplace.

Nonetheless, there is a sense in which the no-blame idea goes against the grain of what some philosophers might consider our 'natural' reactions. In the case of very public organizational disasters, there is a very strong sense in which people seem to need to hold someone accountable, and this seems to be disconnected from considerations around whether this will hamper the process of investigation, or of learning lessons for the future. It is also disconnected from notions of justice that normally underpin formal organizational sanctions. Someone needs to "carry the can', and this can be only tenuously related (if at all) to any causal responsibility they had. Pronouncements by public figures that blame is counter-productive in these circumstances often fall on deaf ears, or stimulate an angry reaction. There seems to be something deep-seated about our desires to blame in these sorts of situations, and the noblame idea arguably runs against the grain of this. Whether this is the case in less serious, and public, 'everyday', organizational failures is an open question. We can say that the 'affective' account would suggest that it might be.

The feasibility and desirability of no-blame needs to be considered in relation to ideas around power and control. Earlier in the article we noted Williams' thought that blame served the function of recruiting people to a moral community whose members share reasons for actions (Williams 1995). It is possible to share Williams' scepticism around this function of blame in society at large; however, it is arguable that work organizations are entities that have a strong imperative to encourage their members to share reasons for action, and may be more effective when they do so. The popular organizational literature is replete with reference to the imperative for organizations to have developed strong cultures and shared values. To the extent to which blaming practices police, preserve, and sustain these, it is questionable whether organizations will have a strong incentive to dispense with them-and of course they may be too deeply entrenched in the culture of the organization to make this possible. Furthermore, blaming is a social practice that is embedded in structure of the social relations in the context in which we observe it. In the context of work organizations, this is the unbalanced power relations of employment relationship. Nietzsche's view of blame as an invention that allows the weak to fire back at the strong is interesting, and may have some purchase on understanding the desire for senior 'heads to roll' in organizational failures. However in organizational settings, it is perhaps more likely that blame will be used politically by those with power to do so, for example, blaming others to shore up one's own position of power or deflect attention from one's own responsibility for error-and there is some empirical evidence for this (Oexl and Grossman 2013; Busby 2006).

The discussion above suggests that there are insights to be gained from applying philosophical ideas to the subject of blame in organizations. Firstly, this helps to locate and unpick the implicit assumptions in the organizational literature around the 'nature' of blame. Secondly, it raises questions about the desirability of doing without blame in organizations, and about the very possibility of doing so. Later in the article we will consider the implications of these ideas, specifically in the context of exploring an alternative to no-blame. Before doing so, we need to "clear the ground' by considering and addressing potential objections to exploring the no-blame idea through the lens of philosophy.

\section{Is the Philosophy of Blame Relevant to Organizational Blame?}

There are three issues to be discussed in establishing the extent to which debates around the philosophy of blame connect with blame in organizations. The first concerns the suggestion that the debate in philosophy concerns 'moral' blame, whereas the blame at issue in the no-blame organizational literature is of a non-moral character. The second concerns the distinction between 'blame' and 'punishment', and the thought that the latter is really what is at issue in the no-blame literature. The third is that blame is a multi-layered concept, and that only some variants of it are addressed by the philosophy, and only some by the organizational literature-and these are not necessarily the same ones.

\section{Moral Blame}

Here we deal with the possibility that, as philosophers are concerned with 'moral' blame, and the no-blame literature is concerned with a much narrower conception of blame as it relates to error-reporting, the discussion of blame in philosophy and organizational literatures has no real connection. It is certainly the case that some of the no-blame literature is concerned with error and organizational responses to it (e.g. Provera et al. 2010). However, it will become clear from our review of that literature-and from the no-blame zeitgeist-that the concept of blame used is much wider in its scope than error-reporting procedures. It encompasses a broader consideration of attitudes and 
behaviours in organizations and how people in organizations should respond to them. For example, excessive risktaking, negligence, bullying, discrimination, and dishonesty may all be things that people may be blamed for in organizations, and all of these arguably (see below) have moral connotations.

In any event, it can be argued that philosophers are not solely concerned with 'moral' blame, or if they are the distinction between moral and non-moral blame is really only one that demarks the distinction between blaming persons and inanimate objects-for example, in the statement 'my car battery is to blame for my being late this morning' (Coates and Tognazzini 2013) — and thus has no traction on the issue in hand. However, the moral/nonmoral distinction might be of the kind that could be used to distinguish between the blame that one might place on someone in ordinary life who has been unfaithful to his wife, and the blame in an organization that might be directed at someone who has made an error in judgment, for example, in recruiting a new member of staff-in which case it could be a highly relevant distinction. Of course, lurking under these questions is the question of what is meant by 'moral' - a core question in philosophy, and not one we can resolve here. However, we feel that there are good grounds for thinking that the moral/nonmoral distinction is not helpful in the current discussion. Firstly, as we have seen, philosophers who are happy to use the term 'moral blame' are also happy to extend its scope beyond deliberately harmful acts to carelessness, neglect, and omissions that damage relations between people. Secondly, there are philosophers (e.g. Owens 2000) who argue for the existence of 'epistemic vices', failures of judgment, and understanding - which are equally likely to be present in organizations - and which merit blame reactions (as much as moral vices such as dishonesty or recklessness). Thus, we follow Williams (1995) in this regard, and suggest that whether or not things are moral, blaming of people is an ethical issue (McGreer 2013), which in all its forms is subject to examination from the perspective of ethical enquiry.

Our conclusion here, then, is that while there may be grounds for identifying different forms of blame (which we discuss below), the moral/non-moral distinction is not the most useful one to make, and does not support a view that philosophical and organizational considerations of blame operate in parallel worlds. The philosophy of blame should have something to say about organizational blaming.

\section{Blame and Punishment}

A second reason for a possible disconnect between philosophy and organizational blame would be acceptance of an argument that the former is about blame and the latter is essentially about punishment. In organizational justice systems, those who break rules or behave badly are subject to disciplinary action, ranging from warnings through to dismissal, which may be seen as equivalent (formally) to punishments in criminal justice systems. As outlined above, and as Shoemaker (2013) points out, many philosophers do equate blame with sanction in this way, and if this is accepted the philosophical discussions would have direct purchase on organizational blame. However, as we discussed, many philosophers do not accept that view of blame, so the distinction between blame and punishment warrants further discussion. Shoemaker himself draws two important distinctions between what he calls 'moral blame' and punishment. Firstly, the former relates not only to actions, but to attitudes. Secondly, moral blame occurs within a community of moral equals, whereas punishment takes place within a system of authority relations. Shoemaker's examples include military sanctions and punishments in the context of parent/child relations. These distinctions can be reasonably extended to systems of organizational sanctions.

It seems clear that some of the discussion on blame in the organizational literature relates to organizational sanctions. The idea behind suspending blame to encourage error-reporting, for example, must include-if it is to have its desired effect-the idea that organizational sanctions (even at the level of an oral warning) will be unpleasant to the recipient. Even so, it is not at all clear that this must be its only element, or that blame in organizations could not occur without any form of sanction. Even without formal organizational sanction, undesirable behaviour might be met with a blame reaction, for example a withdrawal of goodwill and cooperation or a judgement of lack of professionalism - and this reaction may relate to underlying attitudes as well as to actions. Given this, we suggest that the blame/punishment distinction, while an important one, is not one that should preclude consideration of organizational blame in the light of the philosophical literature.

\section{Different Types of Blame?}

Blame has interested philosophers for a number of reasons, but one of most significant arises from the idea that blame is linked to responsibility-we can be (appropriately) blamed from what we can (appropriately) be held responsible for. However, people can be 'responsible' in different senses, and thus may be 'to blame' in different ways. Vincent (2011) identifies six ways in which agents can be responsible: capacity responsibility-whether someone is capable of being regarded as a responsible moral agent in respect of specific events; causal responsibility-whether an event can be connected to an agent's actions; outcome responsibility-a stronger claim as to whether an event can 
be attributed to an agent's actions; role responsibilitywhether an agent's role makes him/her responsible for particular events; virtue responsibility-whether someone is a 'responsible' person in a general sense; and liability responsibility - who or what should be 'held responsible'. Vincent offers a "structured taxonomy" (2011, p. 19) which conceptualizes the relations between these notions of responsibility, and using this it is possible to see how people might be 'to blame' (or not) in different senses. For example, a small child who caused damage or injury at school might be to blame in the 'causal' sense (threw the stone), but not in the capacity sense (on account of their extreme youth), a teacher might be to blame in a 'role' sense (he should have provided adequate supervision), the head teacher might be blamed in the 'outcome' sense (poor supervision, staff training, etc.), and the local education authority held 'liable' (poor systems, failures of governance, etc.).

An important issue in seeking to apply the philosophical literature on blame to the organizational no-blame idea is to be clear as to which form of responsibility/blame is being discussed. One thought might be that no-blame is restricted to causal responsibility—or 'whodunit' (Coates and Tognazzini 2013, p. 7). As we reported above, there is certainly a strong theme in the no-blame literature that reflects this idea, counselling against devoting energy to identifying individual 'culprits' when that energy (and time and cost) could be focused on rectifying systemic failures so that individual errors are less likely to happen in future. However, it was also clear from that discussion that causal responsibility and finger pointing was not all that was at issue. This may even be the case in the case of errorreporting systems. The example from Busby (2006) reported earlier is instructive here-the rail workers were prepared to accept the finger pointing because there was no blame. Moving beyond error-reporting to other arenas for organizational blaming, in the examples quoted (childcare scandals, shipping disasters), role, outcome, and even liability responsibility/blame were at issue. In terms of realizing the espoused organizational learning benefits of noblame, releasing people from the fear of role and outcome blame will be as important as releasing them from the fear of causal blame. After all, in a learning culture managers themselves would need to be 'freed' to allow their staff to make mistakes, confident that they will not be blamed when they do.

In this section, we have explored the extent to which the philosophy of blame has potential traction on the idea of no-blame in organizations. We have examined the relevance of a distinction between moral/non-moral blame to these questions, the relevance of a distinction between blame and punishment, and the relevance of different responsibility/blame concepts. Our conclusion has been that there is still considerable room for the philosophy of blame to do some work in the field of organizational blame. A subsidiary conclusion emerging from this discussion is that the organizational blame literature would benefit from being more explicit and precise in its use of 'blame'-a point that we will return to at the end of the article.

\section{An Alternative to No-Blame?}

Our consideration of the implications of the philosophical literature earlier in the article leads us to some scepticism around the idea of no-blame, at least as to its extended application. However, the philosophical discussion alerts us to the entrenched nature of some of the problems that the no-blame idea was designed to solve-for example the association of blame with power, its inhibiting effect on creativity, innovation and risk-taking, or the emotional and judgmental reactions which may inhibit openness and learning. We suggest that there might be value in exploring alternative ways of addressing these difficulties without letting go of the notion of blaming altogether.

The suggestion that we put forward for discussion is that organization scholars might explore the idea of promoting 'healthier' blaming practices rather than advocating noblame. In the discussion below, we consider what the latter might involve and how it might be underpinned theoretically, but first it is necessary to say how it is conceptually distinct. The sort of approach that we are suggesting shares the core idea of no-blame, namely that blame can be repressive and inhibiting. However, it involves explicit acceptance of two ideas that are absent from the idea of noblame in its more generalized form. First, a recognition that blaming is an inevitable feature of human social interaction and, second, that it has a positive role in human relationships. In theoretical terms, it would draw something from each of the dominant philosophical approaches discussed earlier-recognizing that blame can sometimes (or in part) be an emotional reaction to someone falling short of the organizational standards, sometimes (or in part) a judgment that someone has impaired relations between members of an organization; and sometimes (or in part) a firm reminder that certain values and standards of conduct are expected in that organization. It would incorporate a recognition that each of these may have damaging effects (as identified by no-blame proponents), but retain the idea present in many philosophies of blame, that blame is sustaining of human communities.

In organizational terms, this idea-in contrast to noblame-would find its expression in a clear and explicit commitment to the idea that blaming can have an appropriate role in organizational life, along with a recognition that seeking to dispense with it may in any case be 
impossible. Yet at the same time, it would incorporate a recognition that organizational blaming practices and cultures have the potential to be damaging to constructive and productive work relations. Finding an appropriate balance between these competing imperatives is the challenge here. This will vary with the circumstances of particular organizations, and it is not our intention to offer detailed prescriptions for practice. However, we can offer some thoughts on the principles and theoretical foundations on which these might be developed.

The first thing to say is that restraint and tolerance are likely to be the key underpinning principles in the sort of approach we have in mind. This would avoid what Watson (2013) terms a failure of interpretative generosity. As Kelly (2013, p. 262) notes, “...when we become emotionally invested in negative moral assessments of a person whose failures do not set them apart from most people, we lose sight of our common human frailty". Setting the boundaries around these judgments suitably narrowly is likely to lead to many of the benefits claimed by proponents of noblame, both in terms of managing risk and organizational learning. In terms of risk, we draw parallels with Farson and Keyes' (2002) 'failure tolerant leader'. These authors acknowledge that where organizational members are terrified of failure and of making mistakes, risk-taking may be inhibited. Yet risk-taking is an organizational necessity in many circumstances. Such a leader will encourage a culture of intelligent risk-taking and remove any climate of fear of blame in innovative areas of the operation-while reserving blame for acts of recklessness. Similar observations apply in relation to error and learning. Here, leaders would refrain from blame where individual errors arise from systemic deficiencies and where people make mistakes born of inexperience or lack of training, thus creating a climate where individual and organizational learning can flourish.

The challenge in developing such an approach is in setting the boundaries, for example between recklessness and intelligent risk-taking, or-more generally-the limits of responsible organizational practice. To our mind, these norms are formed within communities of practice (Fuller 2007) in organizational or professional settings. When philosophers talk of blame in relation to (the contravention of) shared values or to what one ought to have done, they refer to obligations within relationships, or human values more generally. In organizational settings, we need to consider the professional, occupational, or organizational values and obligations that set the boundaries for the appropriateness of blaming. These communities of practice not only set these boundaries through their everyday practice, and their reflection on it, but are the context for the development of the appropriate responses to transgression. From this follows a practical implication for leadership development and professional training, in that people learn to blame appropriately within their organizational/professional context, and also learn to be blamed. This suggests that organizations could profitably pay specific attention to developing constructive blaming practices alongside the development of other aspects of leadership and professional ethics (McPherson 2013). Another implication of linking blame with the idea of communities of practice and professional values is that it is possible to see how 'normal' blaming practices may be suspended in specific circumstances (Provera et al. 2010), for example in the airline industry. The development of shared norms and trust, underpinned by the appropriate professional and leadership ethics, may make this possible. However, we return here to an earlier thought, that suspension of our normal blaming tendencies in this way is likely to create tensions and may be difficult to sustain in settings where the imperative to do so is not so strong.

Clearly these ideas would need development and a conceptual underpinning, and providing these is beyond the scope of the current article. We note that this approach has no obvious home within existing philosophies of blame. However, the idea that moderation of one's blaming tendencies is one that may be developed and fostered, and the notion that blaming norms and practice inhabit a community - and are related to the values and development of that community - chime with some of the key ideas in virtue ethics (Foot 2002; Hursthouse 2001). 'Virtue responsibility' also forms part of Vincent's (2011) taxonomy of responsibility concepts, and this merits further exploration in the context of organizational blaming. We are not aware of work which explicitly locates an understanding of blame within virtue theory. Our thoughts in this section suggest that making such a connection might be fruitful in providing a foundation for new approaches to understanding blame in organizations.

\section{Conclusion}

The article began by considering the notion of no-blame, an idea developing in the management literature which draws on the idea that blame may be an inhibitor to organization learning, system improvement, innovation, and risk-taking. We noted that the concept of blame was rarely defined or explored in this literature, and contrasted this with extensive philosophical literature on blame which devotes considerable attention to pinning down this concept - and offers a range of divergent and contested formulations. On the basis of our review of the philosophical literature on blame, we have offered some preliminary thoughts on the light that this can shed on the no-blame idea. Our conclusion here was that the philosophy of blame 
was helpful in forming an interpretation of the concept of blame that is being used-albeit implicitly-in the noblame literature. The conception of blame in the latter was similar to that which sees blame as a sanction (though not necessarily underpinned by a utilitarian view with which this is most commonly associated with in philosophy) and most divergent from affective and relational perspectives that see blame as central to, perhaps constitutive of, normal human social interaction. We also argued that the evaluation of blame, such that might inform an organizational desire to dispense with it, cannot be entirely separated from an understanding of what blame is.

Given this, if the blame at issue in organizations (or at least some of it) is of the affective type, there may be considerable challenges in dispensing with it, even if that were thought to be conducive to organizational ends. This led us to the thought that while no-blame might be practicable and desirable in some restricted organization settings, an acceptance of blaming, but a tempering of its application, might be more realistic and productive more generally.

The no-blame idea is an interesting one in organizational studies, with the potential (rightly) identified by its proponents to make organizations more effective and better places to work. We have identified a need for the idea to be placed on a more secure conceptual footing, and have argued that application of the philosophy of blame has potential to do that. Our discussions here have only been a foundation for that endeavour, though hopefully a useful one, and we make some recommendations as to how this project might be taken forward.

The first is that work should be done to clarify the blaming concepts at play in work organizations. Vincent's (2011) taxonomy of responsibility concepts offers a framework for doing this. This would be a foundation for a more precise articulation of which forms of blame are, and should be, subject to the no-blame idea.

The second represents a call for empirical work to explore blaming practices in organizations. In the absence of this, a detailed understanding of how and why blame happens at work and with what effect is lacking. Our review of the philosophical literature on blame offers the basis of a conceptual framework for researchers to do this.

The third is to explore and develop alternatives to noblame. In the previous section, we sketched out the basis for one such approach, and we recognize there are doubtless other ways of approaching this. Our own suggestion located the development of blaming norms within communities of organizational and professional practice and emphasized that blaming practices are learnt in this context. We also suggested that restraint and tolerance might be appropriate principles underpinning the development of organizational blaming norms. This led us to suggest virtue ethics as a possible framework for developing an alternative to no-blame. Doing so would complement existing efforts to apply virtue ethics to organizational decisionmaking and behaviour (Crossan et al. 2013; McPherson 2013), and would be an interesting and potentially fruitful line of enquiry for researchers to pursue.

To conclude, the contribution of this article has been to open a dialogue between the philosophy of blame and the organizational literature on blame, and to identify the nature of that conversation and where it might lead. This will be useful for organization scholars in developing the idea of no-blame, or indeed alternatives to it. We also hope that it will stimulate some debate.

Open Access This article is distributed under the terms of the Creative Commons Attribution 4.0 International License (http://crea tivecommons.org/licenses/by/4.0/), which permits unrestricted use, distribution, and reproduction in any medium, provided you give appropriate credit to the original author(s) and the source, provide a link to the Creative Commons license, and indicate if changes were made.

\section{References}

BBC. (2011). Shoesmith: I don't do blame. Retrieved May 11, 2015, from http://news.bbc.co.uk/today/hi/today/newsid_9499000/ 9499424.stm

BBC. (2015). Harriet Harman warning over labour blame game. Retrieved May 11, 2015, from http://www.bbc.co.uk/news/ukpolitics-32686769

Bennett, J. (1980). Accountability. In Z. Van Straaten (Ed.), Philosophical subjects: Essays presented to P.F. Strawson (pp. 14-47). Oxford: Clarendon Press.

Busby, J. (2006). Failure to mobilize in reliability-seeking organisations: Two cases from the UK railway. Journal of Management Studies, 43(6), 1375-1393.

Coates, J., \& Tognazzini, N. (2013). The contours of blame. In D. Coates \& N. Tognazzini (Eds.), Blame: Its nature and norms (pp. 3-26). New York: Oxford University Press.

Crossan, M., Mazutis, D., \& Seijts, G. (2013). In search of virtue: The role of virtues, values and character strengths in ethical decision making. Journal of Business Ethics, 113, 567-581.

Farson, R., \& Keyes, R. (2002). The failure-tolerant leader. Harvard Business Review, 80, 64-71.

Foot, P. (2002). Virtues and vices and other essays in moral philosophy. Oxford: Oxford University Press.

Franklin, C. (2013). Valuing blame. In D. Coates \& N. Tognazzini (Eds.), Blame: Its nature and norms (pp. 207-233). New York: Oxford University Press.

Fuller, A. (2007). Critiquing theories of learning and communities of practice. In J. Hughes, N. Hewson, \& L. Unwin (Eds.), Communities of practice: Critical perspectives (pp. 17-29). London: Routledge.

Goldman, D. (2014). Modification of the reactive attitudes. Pacific Philosophical Quarterly, 95, 1-22.

Gronewold, U., Gold, A., \& Salterio, S. (2013). Reporting self-made errors: The impact of organizational error-management climate and error type. Journal of Business Ethics, 117, 189-208.

Holmes, A. (2010). A reflection on the Bushfire Royal CommissionBlame, accountability and responsibility. Australian Journal of Public Administration, 69(4), 387-391. 
Hursthouse, R. (2001). On virtue ethics. Oxford: Oxford University Press.

Kelly, E. (2013). What is an excuse? In D. Coates \& N. Tognazzini (Eds.), Blame: Its nature and norms (pp. 224-243). New York: Oxford University Press.

Lang, J. (2013, January 21). Taking sides on cruise safety. Nautilus Telegraph. Retrieved June 15, 2015, from http://content.yudu. com/Library/A20fuf/NautilusTelegraphJan/resources/21.htm

Levy, N. (2005). The good, the bad and the blameworthy. Journal of Ethics and Social Philosophy, 2, 2-16.

McGreer, V. (2013). Standing in judgment. In D. Coates \& N. Tognazzini (Eds.), Blame: Its nature and norms (pp. 27-48). New York: Oxford University Press.

McPherson, D. (2013). Vocational virtue ethics: Prospects for a virtue ethics approach to business. Journal of Business Ethics, 118, 283-296.

National Advisory Group on the Safety of Patients in England (NAGSPE) the "Berwick Report". (2013). Improving the safety of patients in England: A promise to learn-a commitment to act. Retrieved June 15, 2015, from https://www.gov.uk/government/ uploads/system/uploads/attachment_data/file/226703/Berwick_ Report.pdf

Nietzsche, F. (1997). Beyond good and evil. New York: Dover.

Nietzsche, F. (2003). The genealogy of morals. New York: Dover.

Oexl, R., \& Grossman, Z. (2013). Shifting the blame to a powerless intermediary. Experimental Economics, 16, 306-312.

Owens, D. (2000). Reason without freedom. London: Routledge.

Owens, D. (2012). Shaping the normative landscape. Oxford: Oxford University Press.

Pereboom, D. (2001). Living without free will. Cambridge: Cambridge University Press.

Provera, B., Montefusco, A., \& Canato, A. (2010). A 'no blame' approach to organizational learning. British Journal of Management, 21, 1057-1074.

Scanlon, T. (2008). Moral dimensions. Cambridge, MA: Harvard University Press.

Schilling, J., \& Kluge, A. (2009). Barriers to organizational learning: An integration of theory and research. International Journal of Management Reviews, 11(3), 337-360.
Senge, P. (2006). The fifth discipline: The art and practice of the learning organization. London: Random House.

Sher, G. (2006). In praise of blame. Oxford: Oxford University Press. Smith, A. (2013). Moral blame and moral protest. In D. Coates \& N. Tognazzini (Eds.), Blame: Its nature and norms (pp. 27-48). New York: Oxford University Press.

Strawson, P. (1974). Freedom and resentment, and other essays. London: Methuen.

Tilly, C. (2008). Credit and blame. Princeton, NJ: Princeton University Press.

Tjosvold, D., Yu, Z.-Y., \& Hui, C. (2004). Team learning from mistakes: The contribution of cooperative goals and problemsolving. Journal of Management Studies, 41(7), 1223-1245.

Uribe, C., Schewekhard, S., Dev, S., \& Marsh, G. (2002). Perceived barriers to medical-error reporting: An exploratory investigation. Journal of Healthcare Management, 47(4), 263-280.

Vince, R., \& Saleem, T. (2004). The impact of caution and blame on organizational learning. Management Learning, 35(2), 133-154.

Vincent, N. (2011). A structured taxonomy of responsibility concepts. In I. van der Poel, J. van den Hoven, \& N. Vincent (Eds.), Moral responsibility: Beyond free will and determinism. New York: Springer.

Wallace, R. (1994). Responsibility and the moral sentiments. Cambridge, MA: Harvard University Press.

Wallace, R. (2008). Dispassionate opprobrium: On blame and the reactive sentiments. University of Berkeley. Retrieved July 22, 2010, from www.philosophy.berkeley.edu/file/461/Blame.pdf

Waring, J. (2005). Beyond blame: Cultural barriers to medical incident reporting. Social Science and Medicine, 60(9), $1927-1935$.

Watson, G. (2013). Standing in judgment. In D. Coates \& N. Tognazzini (Eds.), Blame: Its nature and norms (pp. 282-302). New York: Oxford University Press.

Weick, K., \& Sutcliffe, K. (2001). Managing the unexpected. Assuring high performance in and age of complexity. Hoboken, NJ: Wiley.

Williams, B. (1995). Making sense of humanity, and other philosophical papers. Cambridge: Cambridge University Press. 